\title{
Encouraging Sustainable Behaviour Change via a Social Practice Approach: A Focus on Apparel Consumption Practices
}

\author{
M. G. McEachern ${ }^{1}$ (D) D. Middleton ${ }^{2} \cdot$ T. Cassidy $^{3}$
}

Received: 19 November 2018 / Accepted: 9 March 2020/Published online: 31 March 2020

(C) The Author(s) 2020

\begin{abstract}
To encourage greater sustainability regarding apparel consumption practices, policymakers have traditionally focused on economic and/or social psychology frameworks which rely on information-based campaigns to achieve behavioural change. Whilst such campaigns have had limited success and received significant criticism, additional policy solutions are called for. In contrast to conventional behavioural change strategies, this study responds to calls for further methodological insight and explores the potential of creative methods such as upcycling workshops and contemplative theatre performance, as practice-based mechanisms to engender a greater understanding of the environmental impact of apparel consumption and help bring about behavioural change to current apparel consumption practice. Via the theoretical lens of behavioural change theory and contemplative performance practice, our findings reveal the dynamic and continuously reshaping nature of the apparel market, in that most of our participants were until recently unaware of the unsustainable nature of the apparel industry. Despite some participants citing barriers, such as a lack of time, peer pressure, and the desire to express a specific social identity, reactions to practice-based methods were overwhelmingly positive. Thus, initiating a more proactive engagement with sustainability issues as well as increased reflection and discussion on how they might modify current apparel consumption behaviours in the future. We conclude by making suggestions for policymakers regarding future sustainability initiatives.
\end{abstract}

Keywords Sustainable apparel consumption $\cdot$ Social practice $\cdot$ Sustainable apparel disposal . Behaviour change · Apparel industry · Upcycling

M. G. McEachern

m.mceachern@hud.ac.uk

Extended author information available on the last page of the article 
The apparel industry is valued globally at $\$ 1.3$ trillion in retail sales globally (Ellen MacArthur Foundation 2017) and is expected to grow to $\$ 1.5$ trillion in 2020 (O'Connell 2019). With the largest markets identified as the European Union, the United State of America (USA), and China, it is no surprise that it is widely criticized for ignoring its significant global environmental impact ${ }^{1}$ (Armstrong et al. 2016; Austgulen 2016; Carrigan et al. 2013). Consequently, numerous calls are made to the apparel sector to adopt a more sustainable "cradle to grave" approach for the apparel supply chain (Carrigan et al. 2013; Harris et al. 2016; Villa Todeschini et al. 2017). However, one of the most challenging aspects for incorporating sustainability into the apparel supply chain is the need to slow down the entire system, which works against the current culture of quick response and fast fashion ${ }^{2}$; thus, finding a sustainable balance between production and consumption is required (Armstrong et al. 2016; Digital Universe 2011). Regardless of any sustainable efforts implemented by industry, it is crucial to engage and persuade consumers to lower their environmental impact when it comes to apparel (Boström and Micheletti 2016).

Consumers and their apparel consumption behaviours play a significant role when it comes to environmental degradation (Carrigan et al. 2013; Schrader and Thøgersen 2011) and, therefore, can potentially have a significant impact on improving apparel sustainability (Harris et al. 2016). Here, excessive consumption habits are the most substantial causes of high volume apparel waste (Carrigan et al. 2013; Fletcher 2008). The transient nature of fashion, or fast fashion trends, is also held accountable (Environmental Audit Committee 2019; Williams 2011), with approximately 50\% of products produced via the fast fashion model being "disposed of in under a year" (McKinsey and Company 2016, cited in Ellen MacArthur Foundation 2017, p. 19). Such behavioural practices generate over 15 million tonnes of waste textiles in the USA alone, approximately twice the amount 20 years ago (LeBlanc 2018). As a consequence of fast fashion cycles and disposal of otherwise functional apparel in the United Kngdom (UK), approximately 1.5 million tonnes of textile waste ends up in landfill, adding an estimated cost to the UK economy of $£ 82$ million (WRAP 2014). If consumers continue to waste materials at this current rate, more than 150 million tonnes of apparel will end up in landfill or be burned by 2050 (Ellen MacArthur Foundation 2017). Consequently, alerting consumers to the magnitude of their apparel consumption practice and of the potential benefits of changing their behaviour is a fundamental part of reducing apparel waste and driving sustainable consumption practices.

Apparel consumption is defined as a "symbolic social practice through which meanings and identities" are performed (Pilcher 2011, p. 129). Building on Schatzki (1996), Warde (2005) defines practice components as follows: understandings (i.e., practical interpretations of what and how to do), procedures (i.e., instructions, rules, and principles of how to do), and engagements (i.e., emotional and normative orientations relating to what and how to do). The social practice of apparel consumption is therefore understood as "bundles of activity" and their "performance entails the integration of a complex array of components, including

\footnotetext{
${ }^{1}$ Apparel manufacturing accounts for $10 \%$ of greenhouse gas emissions and $17-20 \%$ of industrial water pollution (Armstrong et al. 2016). This excludes potentially damaged product that is never offered for sale (Environmental Audit Committee 2019; Williams 2011). Retailers' unsold stock and manufacturing waste significantly contribute to the landfill problem (WRAP 2017). Despite efforts from the likes of Marks \& Spencer's Plan A and H \& M's deposit boxes to return waste clothing to re-purpose for future manufacturing, such efforts are widely criticized for less than $1 \%$ of waste apparel materials being actually recycled into new apparel (Environmental Audit Committee 2019; Ellen MacArthur Foundation 2017),

${ }^{2}$ Fast fashion is a business model that features over-production of apparel which is sold cheaply and subsequently encourages over-consumption and excessive waste (Environmental Audit Committee 2019; WRAP 2017).
} 
materials, skills, norms, conventions, ideas and emotions" (Halkier et al. 2011; Shove 2010; Welch 2017 , p. 244). As a social practice perspective can help contribute new knowledge around behaviour change (Evans et al. 2012), as well as offer mechanisms to help develop policy interventions (Welch 2017), this research aims to focus on the social interactions and processes around the practices of apparel purchases, repair, and disposal.

Traditional policy initiatives to reduce consumption and increase sustainable consumption has typically revolved around "nudge" campaigns such as voluntary eco-labelling mechanisms to help persuade consumers to change behaviour which will then presumably persuade industry to produce more sustainable products (Environmental Audit Committee 2019; Wolff and Schönherr 2011). However, conventional, information/cognitive-based campaigns have largely been unsuccessful (Goworek et al. 2012; Markkula and Moisander 2012; Ölander and Thøgersen 2014; Welch 2017) and widely criticized for being too timid and lacking in ambition with the result that the general public "has remained largely disengaged" from government sustainability campaigns (Business Green 2011; Cooper 2000, p. 49; Villa Todeschini et al. 2017).

Consequently, calls for more innovative policy solutions in motivating consumers to be more sustainable (i.e., reduce consumption and engage in more re-use, repair, and recycling of apparel) have been made (Boström and Micheletti 2016; Hellmann and Luedicke 2018; Thøgersen and Schrader 2012). Additionally, calls for a new evidence base around practiceoriented research have been made (Halkier et al. 2011; Welch 2017). In response to such calls, this study aims to move away from conventional, awareness-raising approaches towards sustainable behaviour change and instead explore the feasibility of a social practice-based approach to influence behaviour change. In so doing, the central research question in our study was: What impact could creative, practice-based methods such as upcycling workshops and contemplative theatre, have upon influencing sustainable apparel consumption? Following Harris et al. (2016, p. 311), who suggest a "combination of interventions is needed" to encourage sustainability action, we argue that a greater understanding of apparel consumption discourses and the role of social practice-based mechanisms as behaviour change toolsets can contribute to policymaking by aiding the effective design of pioneering initiatives to encourage enhanced sustainable behaviour change.

The paper begins with an overview of the literatures on consumer behaviour change and the role of creative, practice-based, methods (e.g., upcycling workshops, theatre performance) as tools to influence sustainable behaviour change. Next, an overview of the exploratory methodology employed in this research is presented, followed by sections addressing our findings, conclusions, and policy recommendations.

\section{Literature Review}

\section{Understanding Sustainable Consumer Behaviour Change}

A low uptake and/or refusal to adopt more sustainable consumption behaviours is often explained by the fact that consumers are struggling to achieve consistency in amalgamating their values and concerns given the demands of their daily lives (Boström and Micheletti 2016; Szmigin et al. 2009). Thus, changing consumer behaviour has been viewed for a long time as the "holy grail" of sustainable development policy (Belz and Peattie 2010; Jackson 2004; Thøgersen and Schrader 2012; Welch 2017; Thøgersen and Schrader 2012; Belz and Peattie 
2010; Jackson 2004). Whilst it is recognized that consumer behaviour can change voluntarily as well as in response to social marketing tactics, a wide range of behaviour change theories have been created, albeit mainly to help design and implement health-related interventions. Originating from neoclassical economics and social psychology, these theories are largely based on the assumption that behaviour is an outcome of a linear and rational process (Hargreaves 2011) that focuses on beliefs, attitudes, and values, otherwise known as the ABC model and embedded in theories of planned behaviour (Shove 2010).

To give brief examples of such models to the reader, one of the earliest behavioural change models was the three-step change theory by Kurt Lewin in 1951 (Burnes 2004). The first stage of this model involves "unfreezing the existing situation." This is followed by the second stage which involves "movement," whereby the newly targeted behaviour (i.e., to reduce environmental impact and/or to ensure apparel can be re-used by someone else) is moved to a new level of stability. The third stage is described as "refreezing" and involves stabilizing the desired behaviour by balancing both driving (e.g., the need to upgrade an older outfit) and restraining (e.g., a lack of knowledge around how to repair/dispose of apparel) forces (Kritsonis 2004). As with many early psychology-based models, this model was criticized for its linear approach and a lack of support to avoid any individual relapse. Following these criticisms, Lippitt et al. (1958) extended Lewin's model to utilize information exchange and emphasize the role of the change agent rather than the process of change itself (Kritsonis 2004). As indicated earlier, however, information campaigns alone appear to have little impact upon behavioural change (Ölander and Thøgersen 2014), especially considering the competing, trade-off consumption decisions made by consumers (Szmigin et al. 2009) which involve advancement and relapse of the desired behaviour (i.e., a flexible form of moving forward in terms of being more sustainable but regressing to a normal unsustainable state in the event of facing barriers) simultaneously. Another theoretical approach which adopts a spiral model of change (as opposed to linear) is Prochaska and Di Clemente's (1986) transtheoretical model (TTH). Due to the fact that many individuals relapse with their efforts to change (e.g., dieting behaviour), the TTH is conceptualized as a process that takes place over five cyclical stages (i.e., Pre-contemplation; Contemplation; Preparation; Action; and Maintenance) so that the individual can learn from each relapse. However, Prochaska et al. (2001) acknowledge that these stages need to be aligned with stage-matched interventions and that a onesize fits all approach, rarely works. This poses a significant weakness in its application to encourage consumers on a global scale to become more sustainable and mindful of the impact of their consumption decisions.

Alternatively, French (2010) proposes that a better mechanism to change consumption behaviour could be social marketing techniques. McKenzie-Mohr (2000) advocates that the first step of social marketing is to understand the barriers that prevent consumers from engaging in an activity. Often this stage is bypassed by policymakers and planners as they often believe they are already familiar with all of the barriers. Based on the identification of this information, Step 2 emphasizes the importance of selecting a desired behaviour and promoting a positive vision of that behaviour to consumers. After designing a plan of action to overcome the barriers (i.e., Step 3), the plan must be piloted and evaluated after implementation (i.e., step 4). The aim here is to overcome motivational barriers and create an encouraging framework for collective progress.

On review of the above frameworks however, the infinite number of "possible determinants and no method of establishing their history, their dynamic qualities, their interdependence or their precise role in promoting or preventing" behaviours (Shove 2010, p. 1275), it is argued that intervention approaches adopted to date by non governmental organizations (NGOs) and 
governments, are insufficient (Ölander and Thøgersen 2014; Villa Todeschini et al. 2017; Wolff and Schönherr 2011) and often oversimplified (Welch 2017). Other criticisms mooted are that the aforementioned approaches are too individualistic and that they ignore the influencing capacity of social relations, material infrastructures, and context (Armstrong et al. 2016; Hargreaves 2011; Shove 2010). Instead, calls for research and policy attention to the connections, alliances, and conflicts between practices are made (Shove 2010; Warde 2005), especially within the contexts of our everyday home life, leisure, and workplace practices. Heras and Tàbara (2014, p. 380) argue that "the complexity of the new global situation demands imaginative ways to engage and boost our collective intelligence" and that "novel methods for transformational learning need to be tested and developed" (see also Welch 2017). Hence, we propose exploring the feasibility of creative, practice-based, methods (e.g., upcycling workshops; theatre performance) as effective tools to influence sustainable behaviour change.

\section{Creative Approaches as Tools for Sustainability Behaviour Change}

Creative, practice-based approaches are wide-ranging and can include writing, painting, music, drama, and textile arts. Aside from the many debates around what creativity is, Kara (2015, p. 12) argues that it predominantly involves "taking things that already exist and making new combinations" rather than creating something from scratch (e.g., re-making an item from deconstructing another apparel item as opposed to using a new piece of fabric to make an apparel item). Aligned with a sustainable approach to changing wasteful apparel approaches is the creative practice of upcycling, whereby garments are broken down into their component parts to redesign new products (Bridgens et al. 2018; Cassidy and Han 2017). Upcycling is described as being different to recycling as materials and components of unwanted goods are not just re-used but are incorporated into new designs which go beyond resolving textile waste management challenges in that it is essentially a new way of thinking as well as a new way of working (Digital Universe 2011).

The practice of upcycling helps to create economic benefits, environmental benefits as well as psychological and social well-being in the form of learning experiences (i.e., understandings, procedures), and feelings of empowerment and relaxation (i.e., engagements) (Bridgens et al. 2018; Sung et al. 2015). However, the lack of textile skills and time is regularly identified as a strong barrier to carrying out creative activities (Fletcher 2008; Harris et al. 2016). Bramston and Maycroft (2013) conclude that upcycling enables consumers to better understand objects, cultures, and experiences when creating new products whilst simultaneously maintaining the attachment value of the original product. Although consumers increasingly recognize the value of keeping clothes for longer (Harris et al. 2016), more needs to be done to ensure less of a gap between an individual's knowledge, action and habits around ways to upcycle and their purchase behaviour when it comes to sustainable apparel practices (Cassidy and Han 2017; WRAP 2017). A social practice perspective is often proposed as a way to resolve attitude-behaviour gaps (Welch 2017), and therefore, it may be constructive to compare creative approaches such as upcycling with more collaborative forms such as theatre.

There is a significant dearth of academic critique around the value of theatre and contemplative practice in the Business and Management literature (the exceptions being Burgess et al. 2017; Thornquist 2018). This is despite the fact that applied theatre projects are seen to produce "integrative narratives" capable of carrying multiplicities of meaning; generate "processes that create possibilities for reflexivity, experiencing and reframing"; and can "connect 
knowledge with action" (Heras and Tàbara 2014, p. 380). Burgess et al. (2017, p. 1) endorse using theatre as an exploratory tool in that it is considered a more "authentic, embodied and collaborative" mode of knowledge production which fares much better than that of traditional information approaches. To ensure the successful transfer of knowledge, performative and theatrical processes must find an effective means by which to engage audiences in the complexities of the environmental issues in question. In their introduction to Research in Drama Education's 2012 Special Edition on Environmentalism, Heddon and Mackey (2012) note that the UK mainstream theatre's attempts to engage in climate change discussions had largely failed. For example, Taylor (2011) wrote that one play felt "too much like a publicservice broadcast that did not tell one much that is new" (cited in Heddon and Mackey 2012, p. 174) whilst an online commentator described it as "thunderous hectoring" and noted that he felt "lectured" (cited in Heddon and Mackey 2012, p. 174). At the other extreme, Heddon and Mackey identify examples in which "environmental issues have been sidelined for human relationship narratives" (2012, p. 174). Of one such, they write: "Despite dialogues of science, 'climate change' felt merely a device for the theatrical development and exploration of three sets of relationships" (Heddon and Mackey 2012, pp. 174-175).

Drawing on the work of Jacques Rancière to evoke the "emancipated spectator" (2009, p. 176), Heddon and Mackey (2012) suggest that "the work of art must leave space for the spectator" (p. 176) to bring to the work "her own gaze" and her ability to translate and appropriate the story to herself. This suggests openness in the meaning-making possibilities offered by the performance experience, and a degree of trust in the ability of spectators to arrive at their own meanings, applicable and actionable in their own lives.

One of the very few theatre-based projects to address sustainability specifically in relation to apparel, Zoe Svendsen's World Factory (2016) represents a novel response to this challenge. Described as "a performance exploring the production-consumption cycle of contemporary consumer capitalism" (Svendsen 2016, p. 137), World Factory takes the form of a participatory game played by the audience members. Cast as the new managers of a Chinese clothing factory, groups of audience members are dealt cards providing them with small amounts of information and a binary choice between potential courses of action. The moral conundrums represented by the cards are designed to provoke conversations, and the group's choices determine their movement through the game, and the consequences with which they must deal. This embeds uncertainty into the process and empowers participants to come to terms with the complexities of the issues they are dealing with.

An alternative tactic is suggested by Thornquist (2018) who is also responding to the specific problem of the over-consumption of apparel whilst retaining positive aspects of apparel usage such as self-expression and personal identity development. As such, he explores "the theoretical potential of dance and dance movement therapy as a practical remedy for overriding the dependence on fashion-conditioned consumer goods" (p. 825) and identifies the role of impulsive and compulsive buying behaviours in over-consumption of apparel, tracing these to a failure of "self-control" (p. 825). Since dance and dance therapy are identified as having, amongst other things, the capacity to cultivate emotional regulation and enhance selfcontrol, Thornquist explores the theoretical possibility that dance interventions could address factors underlying over-consumptive behaviour patterns. Similarly, Eaton et al. (2017) state that "sustainability education requires a kind of pedagogy that sees learning as not only a cognitive endeavor, but also a somatic, affective and ethical one" (p. 7). For these authors, that holistic combination is served by an inclusion of contemplative practices-meditational modalities that holistically cultivate inner and outer awarenesses, and that constitutes the "inner 
work" needed to complement outer efforts in response to "real-world" problems (Zajonc 2009, p. 14). Whilst Prochaska et al. (2001) use the word "contemplation" to signify reflection on an issue, for these authors, contemplation differs from reflective practice (the latter as defined by Schön (1973) and entailing cognitive activity) as Eaton et al. (2017) explain:

Contemplative practice, on the other hand, is characterized by relaxed yet concentrated presence of mind... it is often experienced as opening a space for other forms of understanding even as one is grounded within the space occupied by one's body. The contemplative mind is not about active thinking, but rather holding a space in silence, maintaining an openness that may allow for understanding and knowledge, or for spontaneous or intuitive insight, that does not arise through discursive thought. Contemplation is characterised by a mind attuned to an awareness of itself as it attends to the world (p. 10).

The contemplative gesture of holding one's inner dimensions in awareness (through somatic, cognitive, and emotional registers) whilst attending to the outer world has important connotations for dealing with sustainability issues. Contemplative modalities engage awareness of the affective dimensions of subjective experience and have been shown to cultivate emotion regulation and resilience (Shapiro et al. 2008). This interplay of affective, cognitive, creative, and critical capacities is characteristic of contemplative forms of inquiry which seek to engage the whole person and to recognize their embeddedness in various societal and relational contexts and environments. In fact, there is an "ecological" aspect to contemplative pedagogy insofar as the awareness that is cultivated through meditational practices is attuned to embeddedness, interconnection, and the arising of phenomena in emergent ways.

Whilst there are to date few publications that deal explicitly with contemporary theatre and performance paradigms that embrace contemplative methodologies, there has long been a close relationship between these sets of practices (Sellers-Young 2013). In Art as Contemplative Practice (2017), Michael Franklin notes that etymologically the verb "to contemplate" is related to "the observation of omens realized while gazing with attentive awareness" (2017, p. 34). Contemplation, then, suggests focused attention, absorption, and insight (pp. 34-35). Through quieting the rational mind, a more direct, relaxed, and responsive mode of perception arises which better allows us to be fully present with what is. As a complement to more discursive modes of thinking, contemplative art forms create a supported space in which other ways of knowing may arise.

In bringing together conceptualizations of sustainability and mindfulness, there are a limited number of studies that examine both concepts (Tezel and Giritli 2017). Whilst some studies make the business case for fostering mindful consumption practices (Belz and Peattie 2010; Jackson 2004; Thøgersen and Schrader 2012), few (if any) acknowledge how to bring about sustainable behaviour change. The next section describes our methodological approach to exploring the feasibility of creative, practice-based, methods (e.g., upcycling workshops; theatre performance) as tools to influence sustainable behaviour change.

\section{Methods}

Following a constructionist ontology, this research adopts an interpretivist lens as it allows us to draw upon experiences and contexts, as well as focus on subjective and nuanced perceptions 
as a way to reveal various facets of the topic explored (Guba and Lincoln 1994). Moreover, it is argued that qualitative research is deemed suitable to address policy problems (i.e., in this case, can practice-based methods help to inform the public about the need to reduce the environmental and social impact of the apparel supply chain?) with a view to providing an alternative but effective way of influencing practitioner practices (Silverman 2016; Welch 2017). Therefore, in order to utilize participants' own perspectives in order to better explore and understand how consumers navigate and respond to sustainability cues in the apparel marketplace, mixed qualitative tools were adopted to expand the current state of knowledge, namely focus groups in the context of interactive upcycling workshops and contemplative theatre performances. As creative, practice-based methodological approaches arguably help to more accurately reflect "the multiplicity of meanings that exist in social contexts" (Kara 2015, p. 8), three upcycling workshops $(n=15)$ and three short contemplative theatre performances $(n=26)$ were conducted over the course of 2018 with individuals from the Yorkshire and Humber region of the UK. As much of the existing research around sustainable consumption has taken a predominantly rational and linear approach (Shove 2010; Welch 2017), our adopted creative methods help to explore apparel consumption practices by taking a more practice-based and contemplative approach. Moreover, the added value aspects of adopting more creative-based methods are that it enables researchers to understand social reality as well as "change and improve it" (Hamera 2011, p. 318; Kara 2015). Further details of why and how these research methods were used now follows.

\section{Focus Groups}

A key advantage of focus groups is that they enable participants to feel more at ease (in comparison to in-depth interviews) because not every question is directed specifically to them, and they are able to build upon other participants' input (Mariampolski 2001). The aim of the sampling process for both the interactive workshops and the theatre performance was to gain insight into apparel-related purchase and disposal activities amongst participants and their practices (if any) around adopting a sustainable lifestyle with regard to apparel acquisition and disposal. Therefore, participants featuring a mix of genders and varied age groups were sought using a purposeful open sampling process from our respective organizational email distribution lists and social media. To enable participants to engage fully with discussions around their consumption practices, and comment on their perceptions towards sustainability, all participants were screened prior to recruitment, to ensure that they did take responsibility for their apparel acquisition activities. In all cases, the interaction between the focus group participants was very positive and the majority of participants were proactive in responding to upcycling activities and the drama performance. Prior to and during the research process, ethical considerations were taken into account concerning anonymity and confidentiality. Apart from gender, age, and nationality, no other identifying information was recorded, thus ensuring anonymity. In terms of confidentiality, all data was secured and stored in compliance with General Data Protection Regulations and University ethical research guidelines.

\section{Interactive Upcycling Workshops}

Three workshops took place at a central textile-linked, location. These were led by a professional textile upcycler and each took the format of a 30-40-minutes exploratory focus group, followed by three taught practice sessions (approximately 100 minutes in total) and concluded 
with a final exploratory focus group. No prior upcycling skills were required to attend the workshops, and the three taught upcycling skills, which are illustrated in Figure 1, included darning (i.e., sewing and mending), tufting (i.e., using a variety of materials to tuft and create shapes to add/replace worn fabric), and sashiko (a Japanese decorative stitching technique).

The format of the skillset activities was very much a "show" and "have a go" approach with many participants electing to bring an item of clothing, which was worn-out and in need of repair, to work on. Compared to traditional research methods, whereby focus groups may have been used alone, photographs and video were also taken to record the skillsets learnt by the participants and to take images of the finished, repaired items. This arguably helps to capture more fully, the "lived realities of everyday" (Belk and Kozinets 2005, p. 128) regarding participant engagement with upcycling practices. The advantage of holding practical workshops alongside our focus groups is that we aimed to empower our participants to help bring about more sustainable, behavioural change when it comes to the acquisition/disposal of apparel items.

\section{Contemplative Theatre Performances}

Arts-based research methods are particularly helpful when exploring topics associated with emotion (Kara 2015), such as the consumption and disposal of apparel products. More specifically, Burgess et al. (2017, p. 8) endorse the positive attributes of using performance as a method of data collection as the "experience is one where each person in the shared space is as important as the other, and as dependant on each other, creating a unique experience." In order to engage audiences with the issue of sustainable apparel and to minimize any fashion preference bias, we chose to focus on the iconic white cotton tee shirt as emblematic of apparel more generally. The performance, titled "Clouds in the Cotton Weave" outlines the life-cycle of an imaginary but possible tee shirt: from cotton plant to African landfill, to which the majority of the UK's recycled apparel is transported (WRAP 2017). It is designed to remind participants of the real value, and the real cost, of what might be a very cheap garment in financial terms. The performance text was written, and the production was designed, with the intention to address a number of factors identified in the literature review. Hence, we sought to create a performance intervention that would:

1. Inspire imaginative responses to the problem of sustainable apparel

2. Construct a potentially transformative process, through which participants might alter their basic relationship to the complex issues involved

3. Generate reflexivity and contemplation on the part of the spectator

4. Induce a more affective response to the situation, with embodied and emotional aspects of experience integrated with cognitive aspects

5. Increase the likelihood that existing or newly acquired knowledge would be combined with a deeper motivation to find and take appropriate personal actions

Cognizant of the limitations of the didactic, information-heavy approaches that Heddon and Mackey (2012) identified, and equally wary of emotionally coercive forms of address, the performance sought a "third way" through the contemplative. At the centre of the performance experience, audiences are brought into an extended, guided meditation on the life-cycle of the tee shirt. Following Eaton et al. (2017), the performance is interactive, somatically, and sensorially engaging and utilizes poetic and performative devices to shift audiences into a 


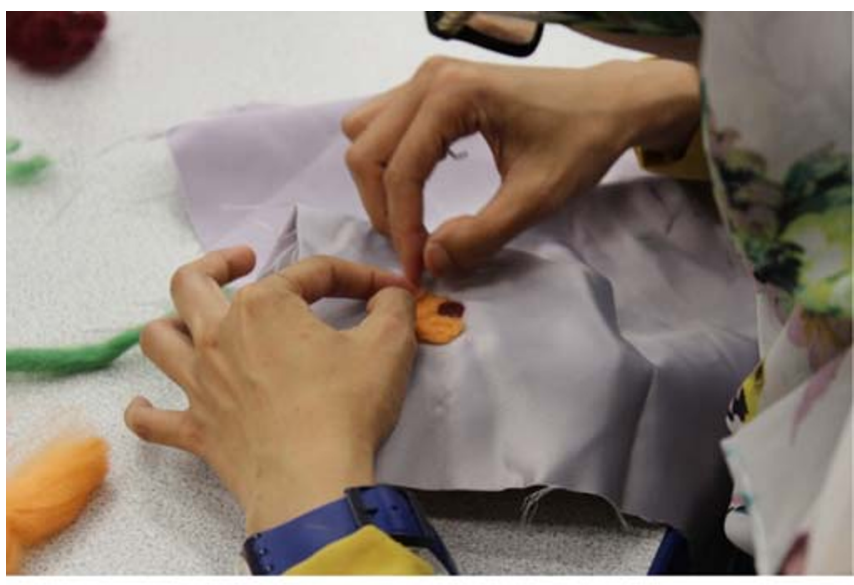

An example of darning

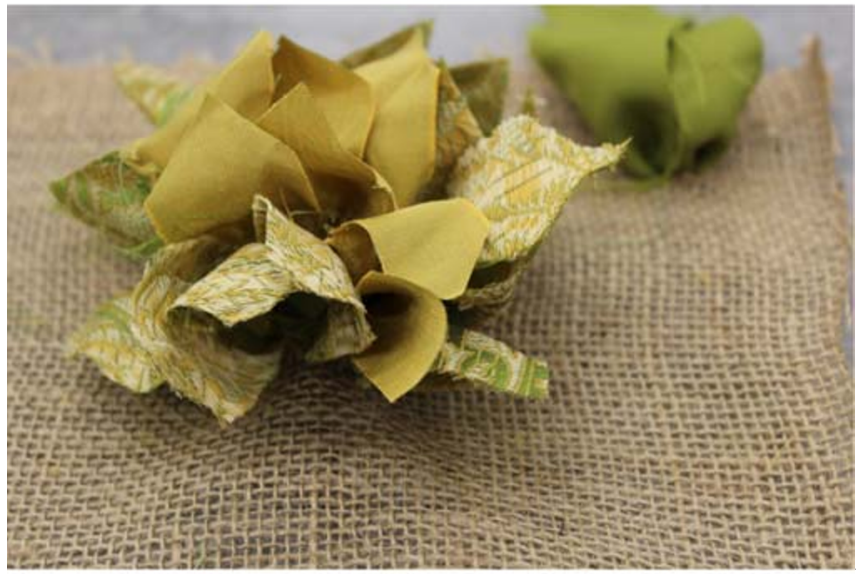

An example of tufting

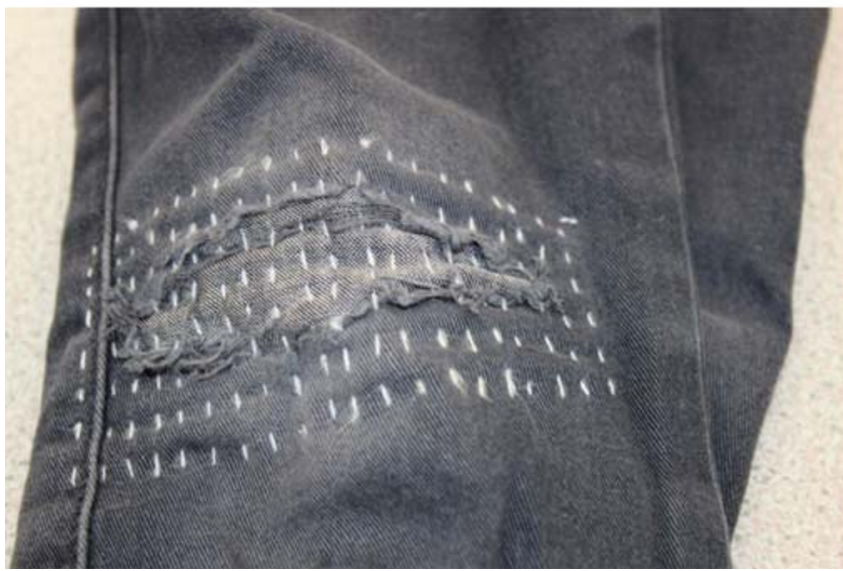

An example of sashiko

Fig. 1 Examples of upcycling activities and outputs 
Table 1 Workshop participant profiles

\begin{tabular}{llll}
\hline Type of activity & Gender/age & Nationality & Description \\
\hline Workshop 1 & Female/24 & British & W1F24 \\
Workshop 1 & Female/64 & British & W1F64 \\
Workshop 1 & Female/27 & Chinese & W1F27 \\
Workshop 1 & Female/57 & Chinese & W1F57 \\
Workshop 1 & Female/34 & Nigerian & W1F34 \\
Workshop 2 & Female/37 & Malaysian & W2F37 \\
Workshop 2 & Female/33 & Malaysian & W2F33 \\
Workshop 2 & Female/31 & Indonesian & W2F31 \\
Workshop 2 & Female/25 & British & W2F25 \\
Workshop 2 & Female/40 & British & W2F40 \\
Workshop 3 & Male/39 & Jordanian & W3M39 \\
Workshop 3 & Female/36 & Jordanian & W3F36 \\
Workshop 3 & Female/38 & Korean & W3F38 \\
Workshop 3 & Female/31 & British & W3F31 \\
Workshop 3 & Female/30 & Korean & W3F30 \\
\hline
\end{tabular}

relaxed and responsive mode of engagement. The final section of the performance brings the participants from their closed-eyes reflection into a gentle group activity, involving handling the tee shirts, in order that the step from contemplation into action is symbolically modelled.

Throughout the performance, interconnectedness is stressed; the production suggests that the consumer of a cotton tee shirt in Europe is separate neither from the other lives that the cotton has passed through (the cotton farmer, the factory workers, the lorry drivers) nor from the life of the planet itself. As Franklin (2017) suggests, contemplative awareness of the ecosystems, of which we are a part, reduces our ability to objectify, diminish, or deny the others whose lives we interact with, albeit at distance. Recognition that we "inter-are" - a phrase coined by Buddhist teacher, Thich Nhat $\operatorname{Hanh}^{3} 77$ - can increase our motivation to change our personal consumption behaviours, knowing that each individual's actions are significant and entail responsibility to a greater whole. The guided meditation at the heart of our performance was modelled on "Interbeing" by Thich Nhat Hanh (1991, p. 95) and designed to cultivate an ecocentric perspective on the part of the participant.

\section{Data Analysis}

Tables 1 and 2 illustrate a general demographic profile of participants who attended our workshops and theatre performances. Although the recruited participants feature a range of age profiles, the upcycling workshops over-feature the female perspective in comparison to the performances which were more evenly split between male and female. This is perhaps expected considering the Western stereotypical association between the role of females and the mending/repair of clothes. With each focus group around both workshops and performances lasting around $3 \mathrm{~h}$, the recordings were used to make "detailed and exacting renditions of the oral record" (Mariampolski 2001, p. 248). From the transcripts, a thematic analysis approach was used to move from description to interpretation (Clarke and Braun 2013). This process involved becoming familiar with the data and generating initial codes; conducting an

\footnotetext{
${ }^{3}$ Thich Nhat Hanh is a scholar and teacher of Buddhist meditation in the context of social change. His teachings include how to apply mindfulness in daily life and in response to environmental challenges. He coined the phrase "interbeing" to reflect the Buddhist concept of the connection and co-dependence of everyone and everything (Hanh 1991).
} 
Table 2 Performance participant profiles

\begin{tabular}{|c|c|c|c|c|}
\hline Type of activity & Gender/age & Nationality & Description & Theatre/mindfulness experience \\
\hline Performance 1 & Female/57 & British & P1F57 & A lot/some \\
\hline Performance 1 & Female/49 & British & P1F49 & A lot/a lot \\
\hline Performance 1 & Female/46 & British & P1F46 & A lot/none \\
\hline Performance 1 & Female/48 & British & P1F48 & Some/a lot \\
\hline Performance 1 & Male/52 & British & P1M52 & Some/some \\
\hline Performance 1 & Male/61 & British & P1M61 & A lot/a lot \\
\hline Performance 1 & Male/36 & British & P1M36 & A lot/some \\
\hline Performance 2 & Male/23 & British & $\mathrm{P} 2 \mathrm{M} 23$ & A lot/some \\
\hline Performance 2 & Female/25 & British & $\mathrm{P} 2 \mathrm{~F} 25$ & Some/none \\
\hline Performance 2 & Female/32 & Indonesian & P2F32 & Some/some \\
\hline Performance 2 & Female/19 & British & P2F19 & A lot/some \\
\hline Performance 2 & Female/25 & British & P2F25 & A lot/some \\
\hline Performance 2 & Female/79 & British & P2F79 & Some/some \\
\hline Performance 2 & Female/52 & British & P2F52 & A lot/some \\
\hline Performance 2 & Male/58 & British & P2M58 & A lot/none \\
\hline Performance 2 & Male/22 & British & $\mathrm{P} 2 \mathrm{M} 22$ & A lot/a lot \\
\hline Performance 2 & Female/74 & British & P2F74 & Some/some \\
\hline Performance 2 & Female/19 & British & P2F19 & None/some \\
\hline Performance 3 & Female/56 & British & P3F56 & A lot/none \\
\hline Performance 3 & Male/65 & British & P3M65 & Some/none \\
\hline Performance 3 & Male/56 & British & P3M56 & A lot/some \\
\hline Performance 3 & Female/65 & British & P3F65 & A lot/some \\
\hline Performance 3 & Female/31 & British & P3F31 & A lot/some \\
\hline Performance 3 & Female/63 & British & P3F63 & A lot/a lot \\
\hline Performance 3 & Male/45 & British & P3M45 & A lot/a lot \\
\hline Performance 3 & Female/24 & British & P3F24 & A lot/some \\
\hline
\end{tabular}

inductive identification and review of themes; followed by the defining, naming, and reporting of themes (Braun and Clarke 2006; Braun and Clarke 2012). Several "passes" were made through each of the transcriptions by each of the researchers, revealing a number of key themes and patterns (Miles and Huberman 1994) as well as meanings associated with each participants' conversation and activities around sustainable apparel consumption and disposal. Thus, revealing the following core themes around: understanding of and interest in sustainability, current sustainable apparel practices, attitudes and feelings towards upcycling/theatre performance, barriers and challenges to being sustainable, and the potential of upcycling/theatre to influence sustainable apparel decisions.

\section{Findings and Discussion}

\section{Pre-workshops and Pre-theatre Performance}

A core theme emerging from our analysis was the understanding of and interest concerning sustainability in the context of apparel consumption. For some, awareness levels and knowledge of sustainability were very high and, thus, played a prominent role in educating other members of the focus group. The complexity, depth of knowledge, and tensions involved in learning about sustainability in this context were captured by one participant who discussed their frustrations with the apparel supply chain: 
I used to wear a lot of cotton. That was the thing I wore most. Then I got really fussed about two things really: What was being sprayed on cotton... and the effect it was having on the cotton workers; and the second thing was about the economies that were being dependent on cotton, so that the people weren't being fed in some areas because cotton was being grown instead, and the money that was being earned from exports wasn't going to feed the people... So all those kinds of things, and the constant kind of negotiation of human rights and questions of ecology (P1).

Only a small minority of participants expressed a long-term interest and commitment to learning about sustainability. For example, "I think I've cared about sustainability from Year 9 [age 13-14] when I first found out about what was happening in the world...I do actively seek to learn about recycling, sustainability" (P1). As seen from the following quotes, most participants' awareness and knowledge appeared to be a recent phenomenon and show the cultural importance of television documentaries (e.g., Sir David Attenborough's Blue Planet II TV programme which documented the impact on our oceans as a result of our waste) and retail industry initiatives (e.g., the Plan A strategy of Marks \& Spencer's and the return schemes practiced by Levi's and H\&M):

I've a thing about man-made fibres, when they wash and you get the fibres being dispersed into the system and then eventually will be in the rivers and oceans and all that kind of thing. That really bothers me, but it's only happened in the last year or so, I guess (P3);

I never really considered sustainability in light of my clothing. But when I walked in to $\mathrm{H} \& \mathrm{M}$, I noticed they have these signs that say 'bring your used clothes in'. So that's when I started thinking about clothing and being sustainable with clothing (WS3).

Moving to consider other influences such as social relations, material infrastructures, and context (Hargreaves 2011; Shove 2010), apparel acquisition practices were mixed. As identified by some studies (Carrigan et al. 2013; Harris et al. 2016; Williams 2011), price, keeping up with fashion trends and socio-cultural influences (e.g., shopping socially as a group) played a prominent role for some participants in influencing their acquisition behaviour. For example, one participant stated that "If I need something or if there's a sale on, and I go on and see something I like, then I'll buy it" (WS1), demonstrating the importance of price and retail marketing efforts as an impetus for buying new apparel. Also observed from many participants was the prominence of conforming to societal expectations when it came to keeping up with fashion trends - "I was very influenced, like, socially, kind of, I feel like I should...you feel like you always wanna look a certain way and look like, top of the trends" (WS2). Additionally, for many participants (mainly female), the frequency of apparel acquisition behaviours arose as a result of engaging in shopping as a socially led, leisure activity, and experiencing peer pressure to buy - "I think it can often be quite a social thing, so we'll go out for lunch, me and my friends, and then we might go, "Do you want to pop in some shops...?" (P3). However, for others, a more visible consideration of sustainability was evident when making apparel purchase decisions. For example, a small minority talked about deliberately buying specific fabric materials due to their sustainable credentials - "I buy synthetics, which loop and keep going" (P1). Other participants discussed the proactive acquisition of apparel through alternative sources such as second-hand/pre-loved outlets and apparel sharing circles - "I'd say that 80 per cent of the clothes that I own are actually second-hand, so they're bought in charity shops, in markets, or me and my friends quite often do swaps" (P3). 
Uniquely adding to the consumer behaviour sustainability literature is the role of financial restrictions and experiences of austerity which also appeared to motivate sustainable behaviour from some participants. For example, "Due to [a]lack of funding or income really, I suppose I've always kind of used sustainable methods to make a home, you know, kind of upcycling things and making cushions out of jumpers and stuff like that, you know. When there's no money you try and, kind of, re-purpose things" (WS2). For some others, preferences for quality over quantity were also identified as a personal strategy to engage in sustainable apparel acquisition behaviours - "I'd rather buy one thing that I see that's good and that I think will last than buy two or three things that are probably fashion - and then I'll look after it and make it last that way" (P3).

Focusing on apparel disposal, behaviour primarily revolved around donating clothes to charity shops. However, rather than appearing fully conscious of the environmental impact of apparel disposal, motivations for participants' behaviour were influenced by the realization that they either had accumulated too many clothes for the storage space available or had changed body shape so that existing clothes no longer fitted. For those participants who were more conscious of the environmental impact, social get-togethers to swap clothes were another strategy adopted to dispose of apparel more sustainably. For example, “...the swap thing, we will set a day, or someone will come round to my house for drinks or something and I'll go, 'I've got all these clothes, do you want to look through them?' We'll sit for two hours and look through clothes and I'll pass them on" (P3).

Narratives around upcycling activities from both our workshops and the contemplative performance were limited, with the most common re-use example involving the conversion of old clothes into cloths for household tasks. A more innovative re-use example came from one participant who discussed her upcycling current projects: 'I've got an old pair of jeans that I've just decided that I can no longer wear. I'm making a bag out of them. My partner's got a shirt that I'm using the lining for that bag, so I think that awareness that I have now has really considerably changed the way that I buy non-disposable clothing" (P1). For other participants, the lack of time for upcycling and a lack of awareness and know-how are the key barriers to this activity:

I'm very aware of [air miles for imported beans], but it's not something that's on my radar in terms of clothes, which is weird, isn't it, because they're all consumer products? (P3); Probably, time is the constraint for me to do more upcycling. And the other reason I can't do upcycling or recycling is because of the fact that I don't know how to treat such materials (WS1).

In support of McKenzie-Mohr (2000), understanding these aforementioned barriers is crucial if policymakers wish to increasingly engage consumers with sustainable apparel activities. Thus, the following section discusses our findings in response to participant involvement with the sustainable practice of upcycling and contemplative theatre performance respectively.

\section{Post-workshops}

Overwhelmingly positive reactions were expressed by our participants towards the upcycling workshops. In support of Bridgens et al. (2018) and Sung et al. (2015), many participants expressed a strong sense of enjoyment, inspiration, and relaxation gained from partaking of the various upcycling techniques. Together with the actual pleasure of taking part, a particularly enjoyable feature of the workshops was the gratification acquired from learning. For example - 
"For me, I think I already have the awareness to do recycling and upcycling. But attending this course, I think I learn more on how I can do the upcycle things by myself and do it simply, not too technically" (WS2). For others, the enjoyment was gained by doing something collaboratively - "It's very relaxing and I really think learning something new as a group is better than doing [upcycling] alone" (WS1). Some participants also reflected upon the contemplative advantages of engaging in upcycling activities - "I've just been lost for three hours, it's been great...It's kind of thinking out of the box really, you know, just even though there's like just three little techniques...So I've found this really inspiring actually" (WS2).

A key observation of the upcycling activity was that there was a great deal of empowerment gained from the taught element of the interactive workshop activities. For example, "It's something that I never thought I'd.... I never thought I'd be able to make that" (WS3). For others, a common reaction for participants was the surprise around the ease of repairs/redesigns that could be created in such a short time and with a limited range of upcycling techniques - "Made me realise that what something so little, something good could come out of it cos, like, looking at the box of stuff [waste fabric samples], I didn't think I'd be going away with something that looks... To me, you could easily buy something like that in, like, Top Shop" (WS3).

For some participants, shared reflections and discussions took place around how learning such upcycling techniques could inform and motivate their future sustainable behaviour. This was particularly evident amongst participants with children from lower socio-economic groups. For example, one participant compared her journey from one of not thinking about sustainability to one where it is now become the norm to think about making apparel last longer - "I guess, in the beginning I never really thought about sustainability in terms of my clothes and how to make them last longer" (WS3). Consequently, some participants wanted to know where they could access additional workshops.

In contrast, some participants questioned the influencing role of upcycling upon their purchase behaviour and instead saw it as a useful tool to influence their disposal behaviour only - "I don't know if it'll affect the way that I purchase clothing cos I'm not sure it will have an effect on that. But it will have an effect on disposing" (WS3). Similarly, for a few participants, a lack of time was cited as a barrier to engaging with upcycling (see also Fletcher 2008; Harris et al. 2016). For example, one participant expressed that "some stuff here needs a lot of time to do...So once you have time you can be interested in doing this" (WS2).

These practice-based upcycling workshops clearly helped to raise participant awareness and understanding of unsustainability in the apparel supply chain but more importantly build our participants' creative and productive relationships with apparel. However, it is useful to explore further how our creative upcycling activities which involve participants functioning as passive recipients of knowledge (see Heras and Tàbara 2014) compared to other creative research approaches such as theatre which aims to evoke a more embodied and reflective experience.

\section{Post-theatre Performance}

In support of Burgess et al. (2017) and Heras and Tàbara (2014), participants on the whole responded very enthusiastically and warmly to the aesthetic experience of the performance. For example, one participant felt that the performance was "[J]just visually beautiful, it's nice 
being involved" (P1). For others, there was much appreciation for the interactive design, and the appeal to the senses - "I really enjoyed that - all my senses were played a little bit. You tasted something. You smelled, you were feeling things. I really enjoyed that" (P2). As observed through the words of one participant - "You were kind of putting people through the experience to have enough of the message to make it stick" (P3). There was evidence that some participants experienced a positive relationship between the performance design and its role in influencing behavioural change with regard to apparel sustainability. This learning process was experienced by some participants as holistic (i.e., as indicated by Eaton et al. 2017) - "I think the way they [the performers] drew attention to scent and touch and the visuals, I think was really, really effective to get you in a different headspace" (P3).

Additionally, for some participants, the affective appeal of the production was significant. For example, one participant described her experience as "I thought the performance was excellent. I entered into it. I was affected by it. I was emotionally affected and I thought it was very, very good" (P3). The aspect to which the audience responded with greatest affect varied from participant to participant. Here, some participants were more highly attuned to text - "I cried at the phrase, 'Little human hopes', it's still making me cry now and it's only three words" (P1). Other participants emphasized the power of the visuals. For example, "I really liked the visual aspect of it. Literally dumping all of our clothes onto the world map and seeing how it travelled" (P2), whereas other participants were drawn more to the collective, practicebased sequences - "... The fact that we were all connected in this one piece of cloth was really quite powerful for me" (P3), thus, suggesting that theatre's ability to convey meaning through multiple modalities might be more impactful and effective in reaching diverse participants.

Following Heddon and Mackey's suggestion that the spectator must be free to arrive at his or her own, personally applicable understandings (2012, p. 176), the contemplative space created by the performance was noted by a number of respondents:

It's an invitation to contemplate... that you can choose to take up or not (P1);

This has been visually and ritually quite calm and quite nice and beautiful and has made you think about what goes on afterwards (P1);

How often do you get the chance to think in depth about that... You don't, do you? You just go and buy a t-shirt (P2).

For some participants, however, the open-ended nature of the reflection combined with the complexity of the issues was frustrating - "I'm left feeling a bit frustrated which I assume is part of the feelings I'm supposed to be left with which is, so what do you do about it then?... that's what theatre's about, isn't it?" (P1). These feelings left many participants asking for further information or guidance - "What it's left me with is that feeling that I do want to know more, I want a nice handout" (P1). Consequently, the performance was criticized by some participants for not providing advice on what individuals could do to be more sustainable and how - "I think if I was ignorant to not knowing other ways of disposing of clothes other than throwing them away, from watching the show I wouldn't know a better way of disposing of them" (P2). These feelings of frustration demonstrate the complexity of changing one's behaviour, especially as there is no single, quick-fix mechanism which will eliminate all behavioural barriers to sustainable apparel consumption.

Nonetheless, as found regarding the role of upcycling workshops being viewed as a form of consumer empowerment (see Bridgens et al. 2018; Sung et al. 2015), our contemplative performance appeared to function as a conduit to inform, motivate, and drive sustainable changes concerning apparel consumption behaviour. In contrast to early positivist, economic/ 
social psychology-based models, a number of participants reported that the performance experience had motivated them to move beyond a stage of "maintenance" (see Prochaska and Di Clemente 1986) and think further for themselves about the dynamic nature of the apparel supply chain and the complex issues involved. For example, one participant felt that the performance "[It's] just highlighted certain things that I didn't know, certain things that metaphorically get you into the right space so that you go, 'Ah', and it makes you think about the whole process" (P3). Others commented upon the impact of the performance as an opportunity to also reflect about other facets of their life regarding sustainability - "I think it gives you that insight in a way to rethink for yourself... if that's looking deeply into one story of cotton and realising how something that you take for granted as a material has that background to it then how many other things in your daily life that you take for granted have a similar thing?" (P1).

Akin to Svendsen's (2016) performance of World Factory, the rich post-performance conversations that were generated suggests that the performance effectively brought our audiences into a more reflective phase. For example, one participant described it as - "It's thinking, is it necessary for you to buy new clothes? That's the first step" (P2). Furthermore, some participants shared specific behavioural changes that they intended to make - "I was never one for buying lots of clothes and disposing of them in unsustainable ways anyway, but... I probably would have carelessly thrown something away. I wouldn't have intentionally done it, but I probably would have, but now I'd be very conscious not to" (P2).

After engaging with such contemplative modalities (see Shapiro et al. 2008), these responses from participants' helped bring together an integrated response which appeared to acknowledge a greater level of embeddedness surrounding the moral conundrums involved between public authorities/institutions, producers (i.e., apparel manufacturers, retailers), and consumers when contemplating changing consumption practices, together with a stronger appreciation of social relations, material infrastructures, and the apparel cultural context.

\section{Conclusions}

This study responds to calls (Boström and Micheletti 2016; Hellmann and Luedicke 2018; Thøgersen and Schrader 2012) for more innovative policy solutions to changing consumption behaviour, and instead of adopting a traditional, rational/information-based approach, we theoretically contribute to a limited social practice, evidence base (Halkier et al. 2011; Welch 2017) by exploring the feasibility of creative, practice-based methods as effective mechanisms to influence behaviour change in the context of apparel consumption practices. Through the practice-based methods of interactive upcycling workshops and contemplative theatre performance, levels of consumer interest, understanding, procedures, and engagements with sustainable consumption were largely positive. Additionally, the findings from both our upcycling workshops and contemplative theatre performances help to positively endorse the value in adopting a social practice approach, especially given the influencing capacity of social relations, material infrastructures, and context, another criticism targeted at previous behaviour change studies (Hargreaves 2011; Shove 2010).

Regarding the creative upcycling workshops, few individuals had any prior experience of upcycling/apparel repair. On completion of the workshops, however, there was a strong sense of empowerment felt by participants in terms of what could be achieved in a short space of time. This is despite a lack of time and a lack of knowledge being cited as barriers to engaging 
previously with this type of activity. Although the practice of upcycling provoked discussion and engaged consumers towards becoming more sustainable, the upcycling workshop was generally attributed as a useful means to behave sustainably concerning disposal practices rather than eliminate and/or reduce acquisition practices.

The performances were generally observed as being highly enjoyable, sociable, and affecting, with the practice-based and contemplative elements strongly valued. Interestingly, the experience of participants was not seen to fall into either of the traps identified by Heddon and Mackey, in that it neither avoided the actual issue of sustainability nor produced an over-informative lecture (2012, p. 174). Moreover, participants readily entered into post-performance discussions about the complexity of the issues involved. However, in contrast to the workshops, some participants reported that they not only felt better informed of sustainability issues as a result of attending and participating in the contemplative theatre performance but also (in many cases) were transformed by the performance experience, as well as motivated to make specific changes to their acquisition/disposal practices. Thus, providing tangible evidence of the constructive, practice-based instrument of contemplative theatre, along with its ability to help consumers, transform their consumption practices to be more sustainable. Additionally, the transformation of our participants (i.e., albeit not based on actual behaviour) suggests that contemplative theatre also has the capacity to assist individuals with the complex, emotional orientation relating to what and how to be (see Warde's 2005 engagements component) sustainable, as many discussed their frustration about identifying the "right thing to do" and, therefore, expressed a desire to actively learn more and participate in further sustainable activities, to help reinforce their intention to change consumption practices.

To support and develop further consumers' sustainable practices, and in line with Harris et al.'s suggestion that a "combination of interventions is needed" (2016, p.311), our research points to the need for a policy to reorient social practices to allow consumers to make better sustainable choices. Thus, we advocate that two streams of sustainability policies should be pursued. One should focus on apparel acquisition practices via a more affective approach such as contemplative theatre performance, and the other should focus on apparel disposal via the practice-based activity of upcycling activities. Additionally, given the complexity of adhering to a sustainable lifestyle, it is imperative that policymakers and NGOs assist the apparel consumer by supporting and/or organizing regular, social practice-based opportunities (e.g., apparel repair days/skills; apparel swaps).Together with these practice-based methods, complimentary resources could be provided in the form of workshops, websites or information sheets. We recognize also, however, that such consumer-targeted initiatives do need to be accompanied by industry initiatives to ensure a slowing down of the apparel system.

As with all research, we acknowledge the limitations around our study. Firstly, we accept that our exploratory approach may not be representative of the whole population. It was never our intention to aim for representativeness but to add to current evidence bases on social practice and explore the feasibility of practice-based methods to influence behaviour change. Finally, our conclusions are not based on revealed, actual changes to acquisition practices and, therefore, we cannot be certain that individuals were not demonstrating signs of social desirability.

Nonetheless, our research indicates that in order to realize sustainable apparel consumption practices and move beyond informational tactics, traditional research can be enriched by using a social practice-based approach to change behaviour. Therefore, in recognition of the 
continuous re-shaping of the apparel marketplace, further mid-term and long-term follow-up research is recommended with a view to investigating the extent to which the upcycling workshop and performance experience can create actual, lasting change through embedding memorable, social experiences which inspire continued, sustainable behavioural change.

Funding Information This study was funded by the University of Huddersfield (2017-2018).

Compliance with Ethical Standards In compliance with the University of Huddersfield's Code of Ethics, our research was approved to conduct research with human participants. Our research followed appropriate research data management practice and observes the Research Council's UK (RCUK) guidelines. The ethical approval procedure of the University of Huddersfield requires researchers to provide participants with a participant information sheet and consent form prior to their participation in the project. The participant information sheet highlighted the rights of the participant to withdraw from the project, to be informed of how their opinions and views will be disseminated and anonymized to remove personal and disclosing information. Participants were also given a deadline to be able to withdraw from the project to minimize its impact on data analysis. Prior to conducting research with our participants, we obtained informed consent from all participants. All data is kept on a secured network drive within the University of Huddersfield. All data was cleaned of all personal/identifiable information to ensure participant anonymity.

Conflict of Interest The authors declare that they have no conflict of interest.

Open Access This article is licensed under a Creative Commons Attribution 4.0 International License, which permits use, sharing, adaptation, distribution and reproduction in any medium or format, as long as you give appropriate credit to the original author(s) and the source, provide a link to the Creative Commons licence, and indicate if changes were made. The images or other third party material in this article are included in the article's Creative Commons licence, unless indicated otherwise in a credit line to the material. If material is not included in the article's Creative Commons licence and your intended use is not permitted by statutory regulation or exceeds the permitted use, you will need to obtain permission directly from the copyright holder. To view a copy of this licence, visit http://creativecommons.org/licenses/by/4.0/.

\section{References}

Armstrong, C. M. J., Connell, K. Y. H., Lang, C., Ruppert-Stroescu, M., \& LeHew, M. L. (2016). Educating for sustainable fashion: Using clothing acquisition abstinence to explore sustainable consumption and life beyond growth. Journal of Consumer Policy, 39(4), 417-439.

Austgulen, M. H. (2016). Environmentally sustainable textile consumption - What characterizes the political textile consumers? Journal of Consumer Policy, 39(4), 441-466.

Belk, R. W., \& Kozinets, R. V. (2005). Videography in marketing and consumer research. Qualitative Market Research: An International Journal, 8(2), 128-141.

Belz, F. M., \& Peattie, K. (2010). Sustainability marketing: A global perspective. Chichester: Wiley.

Boström, M., \& Micheletti, M. (2016). Introducing the sustainability challenge of textiles and clothing. Journal of Consumer Policy, 39(4), 367-375.

Bramston, D., \& Maycroft, N. (2013). Designing with waste. In E. Karana, O. Pedgley, \& V. Rognoli (Eds.), Materials experience: Fundamentals of materials and design (pp. 123-133). Oxford: ButterworthHeinemann.

Braun, V., \& Clarke, V. (2006). Using thematic analysis in psychology. Qualitative Research Psychology, 3(2), 77-101.

Braun, V., \& Clarke, V. (2012). Thematic analysis. In H. Cooper (Ed.), APA handbook of research methods in psychology (Vol. 2, pp. 57-71). Washington: American Psychological Association.

Bridgens, B., Powell, M., Farmer, G., Walsh, C., Reed, E., Royapoor, M., et al. (2018). Creative upcycling: Reconnecting people, materials and place through making. Journal of Cleaner Production, 189, 145-154.

Burgess, G., Kelemen, M., Moffat, S., \& Parsons, E. (2017). Using performative knowledge production to explore marketplace exclusion. Qualitative Market Research: An International Journal, 20(4), 1-8.

Burnes, B. (2004). Kurt Lewin and the planned approach to change: A re-appraisal. Journal of Management Studies, 41(6), 977-1002. 
Business Green. (2011). Coalition green nudge policies are failing, says think tank. Retrieved from. http://www. businessgreen.com/news/2038846/coalition-greennudge-policies-failing-tank. Accessed 11 Aug 2011.

Carrigan, M., Moraes, C., \& McEachern, M. G. (2013). From conspicuous to considered fashion: A harm-chain approach to the responsibilities of luxury-fashion businesses. Journal of Marketing Management, 29(11-12), 1277-1307.

Cassidy, T. D., \& Han, S. L. C. (2017). Upcycling fashion for mass production. In M. A. Gardetti \& A. L. Torres (Eds.), Sustainability in fashion and textiles: Values, design, production and consumption (pp. 148-163). London: Routledge.

Clarke, V., \& Braun, V. (2013). Teaching thematic analysis: Overcoming challenges and developing strategies for effective learning. The Psychologist, 26(2), 120-123.

Cooper, T. (2000). Product development implications of sustainable consumption. The Design Journal, 3(2), 46-57.

Digital Universe. (2011). Upcycling: Re-imagining our waste. Retrieved from http://www.digitaluniverse. net/upcycling/. Accessed 18 Aug 2012.

Eaton, M., Davies, K., Williams, S., \& MacGregor, J. (2017). Why sustainability education needs pedagogies of reflection and contemplation. In M. Eaton, H. J. Hughes, \& J. MacGregor (Eds.), Contemplative approaches to sustainability in higher education (pp. 4-15). New York, NY: Routledge.

Ellen MacArthur Foundation. (2017). A new textiles economy: Redesigning fashion's future. Retrieved from http://www.ellenmacarthurfoundation.org/publications. Accessed 17 Sep 2018.

Environmental Audit Committee. (2019). Fixing fashion: Clothing consumption and sustainability. In 19th February, House of Commons Environmental Audit Committee London: HC 1952.

Evans, D., McMeekin, A., \& Southerton, D. (2012). Sustainable consumption, behaviour change policies and theories of practice. In A. Warde \& D. Southerton (Eds.), The habits of consumption. Collegium (Vol. 12, pp. 113-129). Helsinki: Helsinki Collegium for Advanced Studies.

Fletcher, K. (2008). Sustainable fashion and textiles: Design journeys. London: Earthscan.

Franklin, M. (2017). Art as contemplative practice. New York: SUNY.

French, J. (2010). Why nudges are not enough and why social marketing is part of the answer to the current conceptual confusion evident within state sponsored social improvement programmes. Proceedings from the Institute of Social Marketing, Open University (ISM-Open), Challenging Times, New Challenges, November 2010. Milton Keynes: The Open University.

Goworek, H., Fisher, T., Cooper, T., Woodward, S., \& Hiller, A. (2012). The sustainable clothing market: An evaluation of potential strategies for UK retailers. International Journal of Retail \& Distribution Management, 40(12), 935-955.

Guba, E. G., \& Lincoln, Y. S. (1994). Competing paradigms in qualitative research. In E. G. Guba, Y. S. Lincoln, \& N. K. Denzin (Eds.), Handbook of qualitative research 2 (pp. 163-194). Riverside County: Sage.

Halkier, B., Katz-Gerro, T., \& Martens, L. (2011). Applying practice theory to the study of consumption: Theoretical and methodological considerations. Journal of Consumer Culture, 11(1), 3-13.

Hamera, J. (2011). Performance ethnography. In Handbook of qualitative research (pp. 317-330). Thousand Oaks: Sage Publications

Hanh, T. N. (1991). The miracle of mindfulness: A manual on meditation. London: Random House.

Hargreaves, T. (2011). Practice-ing behavior change: Applying social practice theory to pro-environmental behavior change. Journal of Consumer Culture, 11(1), 79-99.

Harris, F., Roby, H., \& Dibb, S. (2016). Sustainable clothing: Challenges, barriers and interventions for encouraging more sustainable consumer behavior. International Journal of Consumer Studies, 40(3), 309-318.

Heddon, D., \& Mackey, S. (2012). Environmentalism, performance and applications: Uncertainties and emancipations. Research in Drama Education: The Journal of Applied Theatre and Performance, 17(2), 163-192.

Hellmann, K. U., \& Luedicke, M. K. (2018). The throwaway society: A look in the back mirror. Journal of Consumer Policy, 41(1), 83-87.

Heras, M., \& Tàbara, J. D. (2014). Let us play transformations! Performative methods for sustainability. Sustainability Science, 9(3), 379-398.

Jackson, T. (2004). Motivating sustainable consumption: A review of evidence on consumer behavior and behavioral change. Centre for Environmental Strategy, University of Surrey Guildford.

Kara, H. (2015). Creative research methods in the social sciences: A practical guide. Bristol: Policy Press.

Kritsonis, A. (2004). Comparison of change theories. International Journal of Scholarly Academic Intellectual Diversity, 8(1), 1-7.

LeBlanc, R. (2018). Small business: Textile recycling facts and figures. Retrieved from https://www. thebalancesmb.com/textile-recycling-facts-and-figures-2878122. Accessed 16 Nov 2018.

Lippitt, R., Watson, J., \& Westley, B. (1958). The dynamics of planned change: A comparative study of principles and techniques. New York: Harcourt, Brace \& World.

Mariampolski, H. Y. (2001). Qualitative market research: A comprehensive guide. London: Sage Publications.

Markkula, A., \& Moisander, J. (2012). Discursive confusion over sustainable consumption: A discursive perspective on the perplexity of marketplace knowledge. Journal of Consumer Policy, 35(1), 105-125. 
McKenzie-Mohr, D. (2000). Promoting sustainable behavior: An introduction to community-based social marketing. Journal of Social Issues, 56(3), 543-554.

McKinsey \& Company. (2016). Style that's sustainable: A new fast fashion formula in Ellen MacArthur Foundation, A new textiles economy: Redesigning fashion's future. Retrieved from http://www. ellenmacarthurfoundation.org/publications. Accessed 17 Sep 2018.

Miles, B., \& Huberman, M. M. (1994). Data management and analysis methods. In M. K. Denzin \& Y. S. Lincoln (Eds.), Handbook of qualitative research. Thousand Oaks: Sage Publications.

O’Connell, L. (2019). Global apparel market - Statistics and facts. Retrieved from https://www.statista. com/topics/5091/apparel-market-worldwide/. Accessed 13 Jan 2020.

Ölander, F., \& Thøgersen, J. (2014). Informing versus nudging in environmental policy. Journal of Consumer Policy, 37(3), 341-356.

Pilcher, J. (2011). No logo? Children's consumption of fashion. Childhood, 18(1), 128-141.

Prochaska, J. O., \& Di Clemente, C. C. (1986). Toward a comprehensive model of change. In Treating addictive behaviors (pp. 3-27). Boston, MA: Springer.

Prochaska, J. M., Prochaska, J. O., \& Levesque, D. A. (2001). A trans-theoretical approach to changing organizations. Administration and Policy in Mental Health and Mental Health Services Research, 28(4), 247-261.

Rancière, J. (2009). Aesthetics and its discontents. Cambridge: Polity Press.

Schatzki, T. R. (1996). Social practices: A Wittgensteinian approach to human activity and the social. New York, NY: Cambridge University Press.

Schön, D. A. (1973). Beyond the stable state: Public and private learning in a changing society. London: W.W. Norton \& Co..

Schrader, U., \& Thøgersen, J. (2011). Putting sustainable consumption into practice. Journal of Consumer Policy, 34(1), 3-8.

Sellers-Young, B. (2013). Motion in stillness; stillness in motion: Contemplative practice in the performing arts. In J. R. McCutcheon, B. Sellers-Young, \& B. S. Young (Eds.), Embodied consciousness: Performance technologies. New York, NY: Palgrave Macmillan.

Shapiro, S. L., Brown, K. W., \& Astin, J. A. (2008). Toward the integration of meditation into higher education: A review of research. Prepared for the Center for Contemplative Mind in Society. Retrieved from http://www. contemplativemind.org/admin/wpcontent/uploads/2012/09/MedandHigherEd.pdf. Accessed 30 Oct 2018.

Shove, E. (2010). Beyond the ABC: Climate change policy and theories of social change. Environment and Planning A, 42(6), 1273-1285.

Silverman, D. (2016). Qualitative research (4th ed.). London: Sage Publications.

Sung, K., Cooper, T., \& Kettley, S. (2015). An exploratory study on the links between individual upcycling, product attachment, and product longevity. PLATE Conference Proceedings, Nottingham Trent University, 17-19 June 2015, 349-356. Retrieved from. https://www.dora.dmu.ac.uk/handle/2086/14727. Accessed 16 Nov 2018.

Svendsen, Z. (2016). World factory. Performance Research, 21(4), 137-139.

Szmigin, I., Carrigan, M., \& McEachern, M. G. (2009). The conscious consumer: Taking a flexible approach to ethical behavior. In Peattie, K., \& Collins, A. (Eds), Special issue on sustainable consumption. International Journal of Consumer Studies, 33(2), 224-231.

Taylor, P. (2011, February 3). Greenland, National theatre: Lyttelton, London. The Independent. Cited in: Heddon, D., \& Mackey, S. (2012). Environmentalism, performance and applications: Uncertainties and emancipations. Research in Drama Education: The Journal of Applied Theatre and Performance, 17(2), $163-192$.

Tezel, E., \& Giritli, H. (2017). Understanding sustainability through mindfulness: A systematic review. In International Sustainable Buildings Symposium (pp. 321-327). Cham: Springer.

Thøgersen, J., \& Schrader, U. (2012). From knowledge to action-New paths towards sustainable consumption. Journal of Consumer Policy, 35(1), 1-5.

Thornquist, C. (2018). The potential of dance: Reducing fashion consumption through movement therapy. Journal of Cleaner Production, 183, 824-830.

Villa Todeschini, B., Nogueira Cortimiglia, M., Callegaro-de-Menezes, D., \& Ghezzi, A. (2017). Innovative and sustainable business models in the fashion industry: Entrepreneurial drivers, opportunities and challenges. Business Horizons, 60, 759-770.

Warde, A. (2005). Consumption and theories of practice. Journal of Consumer Culture, 5(2), 131-153.

Welch, D. (2017). Behaviour change and theories of practice: Contributions, limitations and developments. Social Business, 7(3-4), 241-261.

Williams, S. (2011, January 16). Sri Lanka upcycling factory makes waves in the fashion industry. The Telegraph, 16 January 2011. Retrieved from http://www.fashion.telegraph.co.uk/news-features/TMG8254833/SriLankan-upcycling-factory-makes-waves-in-the-fashion-industry.html. Accessed 27 Feb 2011. 
Wolff, F., \& Schönherr, N. (2011). The impact evaluation of sustainable consumption policy instruments. Journal of Consumer Policy, 34(1), 43-66.

WRAP (2014). Evaluation of the end markets for textile rag and fibre within the UK. Retrieved from http://www. wrap.org.uk/sites/files/wrap/priv_download/MPD007-015_Evaluation\%20of\%20End\%20Markets_Final. pdf. Accessed 16 Nov 2018.

WRAP. (2017). Valuing our clothes. Retrieved from http://www.wrap.org.uk/sustainable-textiles/valuing-ourclothes. Accessed 30 July 2017.

Zajonc, A. (2009). Meditation as contemplative inquiry. Great Barrington: Lindisfarne Books.

Publisher's Note Springer Nature remains neutral with regard to jurisdictional claims in published maps and institutional affiliations.

\section{Affiliations}

\section{G. McEachern ${ }^{1} \cdot$ D. Middleton ${ }^{2} \cdot$ T. Cassidy ${ }^{3}$}

D. Middleton

d.k.middleton@hud.ac.uk

T. Cassidy

t.d.cassidy@hud.ac.uk

1 Department of Management, The Business School, University of Huddersfield, Queensgate, Huddersfield HD1 3DH, UK

2 Department of Music and Drama, School of Music, Humanities and Media, University of Huddersfield, Queensgate, Huddersfield HD1 3DH, UK

3 Department of Fashion and Textiles, School of Art, Design and Architecture, University of Huddersfield, Queensgate, Huddersfield HD1 3DH, UK 